\title{
Os Primórdios dos Discos Comerciais da Música Tradicional Brasileira
}

\section{Roberto Nunes Corrêa}

Roberto Corrêa é músico e compositor. Bacharel em Física e Música pela UnB, mestrando em Musicologia pela ECA/ USP, ele dedica-se, como instrumentista e pesquisador, desde 1977, ao estudo das violas brasileiras. Possui dezenas de discos lançados. Publicou vídeos e livros de seus trabalhos.

\footnotetext{
${ }^{1}$ Mário de Andrade foi o primeiro diretor do Departamento de Cultura de São Paulo (1934 - 1937), hoje Secretaria Municipal de Cultura.
}

Resumo: O objetivo deste trabalho é traçar o percurso inicial das gravações e edições em discos de acetato, pela indústria fonográfica, da música tradicional brasileira, seja através de Institutos sem fins lucrativos, seja através das gravadoras. No caso da comercialização, procurar identificar as estratégias empregadas pelas gravadoras para atingir e ampliar o público consumidor potencial desse tipo de música.

Palavras-chave: indústria fonográfica; música popular brasileira; Cornélio Pires.

Abstract: The following text describes how the phonographic industry initially recorded and edited the traditional Brazilian music's acetate discs, which occurred both through non-profit institutes and recording companies. In regard to commercialization, the article identifies the strategies employed by the recorders to achieve and enlarge the potential market for that type of music.

Keyword: phonographic industry; brazilian popular music; Cornelio Pires.

\section{O início}

Os discos de acetato começaram a ser fabricados no Brasil no ano de 1902, e esta mídia que, de certa forma, registrava a música popular brasileira e a disponibilizava ao público como produto comercial, foi utilizada também para registrar a música tradicional de nosso povo.

Em 1902 (Frederico Singer, um tcheco de origem judaica, radicado nos EUA) passa a atuar também na gravação de música popular e seus primeiros artistas contratados são os cantores de serenata Antônio da Costa Moreira, o Cadete, e Manuel Pedro dos Santos, o baiano. Nesses primeiros trabalhos, foram registrados choros, lundus, modinhas, além de músicas executadas pela recémcriada Banda do Corpo de Bombeiros (formada pelo maestro e compositor Anacleto de Medeiros, em 1896) (Tinhorão apud Vicente, 2010, p. 79).

Com relação à música tradicional, podemos citar as gravações realizadas por Roquete Pinto, no ano de 1917, com cantos indígenas de Rondônia e as gravações de Luiz Heitor Corrêa de Azevedo no estado de Goiás, no ano de 1942, quando da inauguração da nova capital deste estado.

No ano de 1945, temos a edição de vinte e oito discos com o selo da Discoteca Pública ${ }^{1}$. As gravações foram realizadas no ano de 1938 pela Missão de Pesquisas Folclóricas, projeto do Departamento de Cultura, idealizado por Mário de Andrade. 
Vale louvar a percepção de Mário de Andrade, que, no ano de 1936, quando convidado a redigir o anteprojeto do Serviço de Patrimônio Histórico e Artístico Nacional, propõe, como relata Flávia Camargo Toni, "que as músicas que nosso povo cantava e dançava fossem elevadas à categoria de um bem de cultura imaterial, uma vez que seriam gravadas, filmadas e inclusive catalogadas em livros de tombo."

(...) A parte que inicialmente tem de ser adquirida, e é de necessidade imediata, é o aparelhamento de filmes sonoros, fonografia e fotografia. Mesmo o aparelhamento fotográfico pode ser deixado para mais tarde, embora isto não seja aconselhável. A fonografia como a filmagem sonora fazem parte absoluta do tombamento, pois que são elementos recolhedores. Da mesma forma com que a inscrição num dos livros de tombamento de tal escultura, de tal quadro histórico, dum Debret como dum sambaqui, impede a destruição ou dispersão deles, a fonografia gravando uma canção popular cientificamente ou o filme sonoro gravando tal versão baiana do Bumba-meu-boi impedem a perda destas criações, que o progresso, o rádio, o cinema estão matando com violenta rapidez (Andrade apud Toni, 2004, p. 45).

No entanto, o anteprojeto, infelizmente, não foi aprovado. Mário de Andrade transfere, então, para a Discoteca Pública o seu ideal de mapeamento musical do Brasil, o que de fato acontece em parte, com a viagem da Missão de Pesquisas Folclóricas, em 1938, pela região norte e nordeste do país.

O desinteresse por parte do governo no mapeamento musical do Brasil acontece também com as gravadoras, que, por razões comerciais, não acreditam na viabilidade do produto. É importante reproduzir o trecho do livro de J. L. Ferrete, Capitão Furtado: viola caipira ou sertaneja?, a respeito desse desinteresse da indústria fonográfica.

Downey (Wallace Downey, diretor norte-americano da Gravadora Colúmbia em São Paulo no ano de 1929) encaminhou Cornélio Pires ao proprietário da empresa, Byington Jr. Este, para não fugir à regra geral do preconceito quanto ao 'não-artístico', rejeitou a proposta de Cornélio Pires para que se gravassem discos com material caipira autêntico em seu selo. "Não há mercado para isso, não interessa." (Ferrete, 1985, p. 39).

\section{A quebra de paradigma sobre a comercialização de discos de música tradicional}

Cornélio Pires, em uma iniciativa pioneira em 1929, modifica esse olhar de que discos de cultura tradicional não seriam consumidos pelo povo.

De forma independente, banca a confecção de cinco discos de 78rpm, na fábrica Colúmbia, e passa a divulgá-los nos programas de rádio. Em pouco tempo, vende estes discos e desperta no então presidente da fábrica Colúmbia, Byington Jr., o interesse em produzir mais discos desta cultura caipira. Cornélio aceita a oferta de Byington Jr. e produzem um total de quarenta e oito discos.

Como relata J. L. Ferrete:

A notícia da existência dos discos caipiras de Cornélio Pires no interior do estado alvoroçou o interior paulista, de Jundiaí a Assis, de Sorocaba a São José do Rio Preto. Todos queriam essas gravações, mesmo com preço dois mil-réis mais alto. O próprio Byington Jr. reconheceu que havia errado em seus prognósticos e, desenxavido, propôs ao patrocinador da série que sua empresa distribuísse os discos. Muitas lojas da capital os estavam reclamando insistentemente e havia gente que tentava comprá-los na fábrica (Ferrete, 1985, p. 40). 
${ }^{2}$ Trecho assinado por Antônio Cândido na parte interna do LP CAIPIRA - raizes e frutos, com Mineiro e Manduzinho, Pedro Chiquito, Adaulto Santos, entre outros, lançado no ano de 1980, pela gravadora Estúdios Eldorado LTDA.
Vale ressaltar que as músicas levadas a disco por Cornélio Pires eram, de certo modo, uma "redução" das tradições musicais caipiras e não as manifestações em si, assim como eram praticadas nos eventos devocionais e sociais nas comunidades rurais do interior paulista. No entanto, estas gravações foram determinantes para o estabelecimento e popularização das duplas caipiras.

Sobre a região tida como caipira transcrevemos a seguir, de Antônio Candido, trecho de seu texto O Mundo do Caipira, publicado na parte interna do LP CAIPIRA - raízes e frutos, lançado no ano de 1980 por Estúdios Eldorado LTDA, com a coordenação musical de Aluízio Falcão.

Na verdade, o caipira é de origem paulista. É produto da transformação do aventureiro seminômade em agricultor precário, na onda dos movimentos de penetração bandeirante que acabaram no século XVIII e definiram uma extensa área: São Paulo, parte de Minas Gerais e do Paraná, de Goiás e de Mato Grosso, com a área afim do Rio de Janeiro rural e do Espírito Santo. Foi o que restou de mais típico daquilo que um historiador grandiloquente mas expressivo chamou de "Paulistânia"2.

Estas gravações de Cornélio Pires pela Colúmbia inauguram um novo cenário para a música de origem rural. No entanto, esse novo "fazer musical" fica sujeito a critérios limitadores tanto no que diz respeito ao produto em si quanto às regras de um mercado em construção. A esse tipo de música o sociólogo José de Souza Martins denominou de música sertaneja, diferenciando-a, principalmente por este aspecto comercial, do que ele denominou de música caipira, aquela ligada às circunstâncias sociais e devocionais do povo interiorano.

Sobre esta diferenciação, o autor escreve:

Esse ponto (ponto de distinção entre a música caipira e a música sertaneja) está no uso da música caipira, isto é, no fato de que ela se caracteriza estritamente por seu valor de utilidade, enquanto meio necessário para efetivação de certas relações sociais essenciais ao ciclo do cotidiano do caipira. Sem a música essas relações não poderiam ocorrer ou seriam dificultadas, acentuando a crise da sociabilidade mínima dos bairros rurais, como aliás se observa naqueles que estão em desagregação (Martins, 1975, p. 112).

\section{A mobilização do governo na documentação das tradições musicais brasileiras}

A partir da segunda metade do século passado, há um interesse crescente por parte das instituições ligadas ao governo de se registrar a música do nosso povo. Esse interesse coincide com uma iniciativa da Unesco, que após o término da segunda guerra liderou um movimento que procurava implantar mecanismos para documentar e preservar tradições culturais que, avaliavam, estariam em vias de desaparecimento.

No Brasil, atendendo a esta diretriz, em 1947 criou-se a Comissão Nacional do Folclore vinculada à Unesco e, em 1958, instalou-se a Campanha de Defesa do Folclore Brasileiro (CDFB), vinculada ao então Ministério da Educação e Cultura.

Em 1976, a CDFB foi incorporada à FUNARTE como Instituto Nacional do Folclore (INF) e, em 2003, passa a integrar a estrutura do IPHAN como Centro Nacional de Folclore e Cultura Popular (CNFCP) ${ }^{3}$.

A CDFB, e posteriormente o INF, publica uma coleção de compactos e LPs com gravações de manifestações musicais tradicionais de algumas regiões do Brasil. Nesta série, cujos discos não podiam ser vendidos, nota-se que estão praticamente ausentes as manifestações tradicionais da região tida como caipira. 


\section{Os primórdios da comercialização de discos da música tradicional brasileira}

Excluindo o caso da música da cultura caipira levada ao disco a partir da iniciativa de Cornélio Pires, que, como sabemos, percebeu o interesse de um público consumidor em potencial, qual seria a recepção do público consumidor para os discos de manifestações tradicionais? E, ainda, haveria demanda para este tipo de música que justificasse um investimento por parte das gravadoras?

Interessa-nos saber, então, como se deu o processo de apresentação destas manifestações em disco para o público consumidor por parte das gravadoras.

Para tentar responder a estas perguntas, vamos nos reportar aos primeiros discos comerciais lançados com material dito folclórico.

No ano de 1956, a gravadora Copacabana lança o LP Danças Gaúchas, com Inezita Barroso acompanhada por Titulares do Ritmo e Luiz Gaúcho no acordeom. O disco era parte essencial de um projeto de difusão das danças gaúchas, recolhidas e adaptadas por Barbosa Lessa e Paixão Côrtes, e complementaria o livro Manual de Danças Gaúchas, destinado ao ensino primário, que explicava detalhadamente a execução dos passos e sapateios de cerca de 25 danças típicas sul brasileiras.

\footnotetext{
${ }^{4}$ Trecho não assinado na contracapa do LP Danças Gaúchas, com Inezita Barroso, Grupo folclórico de Barbosa Lessa e Luiz Gaúcho à sanfona. Lançado no ano de 1956 pela gravadora Copacabana.
}

\begin{abstract}
O serviço de pesquisas durou dois anos e meio, durante os quais Paixão Côrtes e Barbosa Lessa visitaram 62 municípios sul-rio-grandenses. Recolhido farto material, seguiu-se a reconstituição das coreografias pesquisadas, bem como - visando melhor receptividade por parte do grande público - a adaptação dos respectivos textos musicais. (...) Se há indiscutivel mérito cultural no presente disco, não menos expressivo, por certo, é o seu valor artístico, visto que a execução vocal foi entregue a essa incomparável intérprete de nosso populário - Inezita Barroso, que aqui se faz acompanhar pelos Titulares do Ritmo e pelo acordeom de Luiz Gaúcho. Ninguém melhor que ela, alias, para transpor do plano estadual sul-rio-grandense para o plano nacional, esse rico patrimônio artístico-tradicional que o gaúcho nos desvenda. Inezita, mais uma vez, estará demonstrando que as tradições gaúchas não são menos brasileiras que as de outros Estados da Federação ${ }^{4}$.
\end{abstract}

Nove anos depois deste lançamento, em 1965, é lançado no estado do Paraná o LP Gralha Azul - Folclore do Paraná, com a cantora Ely Camargo e Orquestração de George Kaszás, talvez inspirado na reedição do LP Danças Gaúchas de Inezita Barroso, em 1961, com arranjos para Orquestra de Hervê Cordovil.

Este disco, que tinha Aramis Millarch na coordenação de textos e pesquisa, apresenta uma recriação da tradição musical paranaense, haja vista não ter participante oriundo desta tradição. O texto na parte interna do disco nos revela dados curiosos a respeito de sua produção.

Ao ser idealizado e produzido há 23 anos passados, Gralha Azul (Folclore Paranaense) nasceu de forma que pudesse alcançar amplas faixas de público e não apenas como um documento etnográfico, com o som original do folclore paranaense.

(...) o produtor Inami Custódio Pinto concebeu o disco como uma forma de alcançar o maior número de ouvintes e não apenas para um grupo de iniciados e estudiosos.

(...) Paranaenses simpáticos a manifestações musicais, dedicaram-se ao projeto, avalizando os custos. O disco foi prensado e lançado, mas as vendas não foram suficientes para custear o investimento. Solheite (Carlos Francisco Solheite), hoje com 51 anos (1988), recorda que, para honrar os compromissos, teve que se desfazer do único bem que possuía: um reluzente automóvel Volkswagen, zero quilometro.

(...) Da primeira edição de mil exemplares, mais da metade foi distribuída 
${ }^{5}$ Trechos não assinados na parte interna do LP Gralha Azul, reeditado pela Secretaria da Cultura do Paraná, no ano de 1988.

${ }^{6}$ Trecho do depoimento de Pena Schmidt concedido a Eduardo Vicente em setembro de 2007, dentro do projeto "O Outro Lado do Disco: a Memória Oral da Indústria Fonográfica no Brasil."

\footnotetext{
${ }^{7}$ Trecho assinado por Rossini Tavares de Lima na contracapa do LP Gralha Azul (Folclore do Paraná) com Ely Camargo, Orquestra de Cordas, Percussão, Regional do Miranda, Côro misto e o grupo Titulares do Ritmo, com a direção musical de George Kaszás. Lançado no ano de 1965, pela gravadora Chantecler.
}

\footnotetext{
${ }^{8}$ Trecho assinado por Rossini Tavares de Lima na contracapa do LP A Verdadeira Quadrilha de São João, temas recolhidos por Rossini Tavares de Lima e Oneyda Alvarenga, com Alberto Calçada e conjunto Chantecler, tendo como marcador Moraes Sarmento.
}

gratuitamente. Posteriormente, houve segunda prensagem, já por iniciativa da própria Chantecler, mas excluindo o encarte. Esta vendeu razoavelmente bem $^{5}$.

Dois deles são dignos de comentário. O primeiro diz respeito à última frase "Esta vendeu razoavelmente bem" (a segunda prensagem do LP por conta e risco da própria gravadora). Isso suscita a seguinte pergunta: qual seria a quantidade de discos lançados no mercado, na época, que cobriria os custos de produção e qual a margem de lucro que compensaria e justificaria o investimento por parte da gravadora?

O segundo diz respeito à possibilidade de se contratar os serviços da gravadora para a produção de discos. Esta modalidade praticada pela indústria está muito bem relatada no artigo de Eduardo Vicente, Chantecler: uma gravadora popular paulista.

(...) A gravação e impressão de discos sob demanda não é um comportamento tradicional das gravadoras. Porém, a ação da Continental (na época, Colúmbia) em relação a Cornélio Pires, provavelmente pelo seu sucesso, levou a empresa a manter, durante boa parte de sua existência, um departamento destinado especificamente a oferecer esse tipo de serviço, denominado "matéria paga" (Vicente, 2010, p. 79-80).

(...) "Isto é a matéria paga, você faz por encomenda, usa o know-how da empresa, os arranjadores,, o carimbo de 'disco da continental'... Muita coisa, muito artista da Continental entrou como matéria paga." ${ }^{6}$

\section{Iniciativas das gravadoras de formar público consumidor}

Retornando ao tema do posicionamento das gravadoras com respeito à música tradicional, na contracapa da primeira edição do LP da Chantecler Gralha Azul, de 1965, o folclorista Rossini Tavares de Lima nos revela, de forma clara, a postura que a gravadora tinha para esse tipo de música: "No atual lançamento, a Chantecler prossegue no seu intento de oferecer ao grande público, na programação de aproveitamento de material folclórico e nas possibilidades de disco comercial, o que existe de mais expressivo no domínio da música espontaneamente criada e aceita pelas diferentes coletividades brasileiras." ${ }^{7}$

Com respeito à gravadora Chantecler, é digno de nota o papel desempenhado por Biaggio Baccarin, seu diretor artístico mais atuante, que produziu a Série de Folclore Brasileiro da gravadora, inaugurada com o LP A Verdadeira Quadrilha de São João.

Na apresentação desse disco, o folclorista Rossini Tavares de Lima o cita da seguinte forma:

Este disco nasceu de uma idéia que começou a germinar há um ano ou pouco mais. A idéia, porem, não é minha, mas do amigo Braz (Biaggio Baccarin), diretor artístico da Chantecler e entusiasta afeiçoado da música brasileira, erudita, popular ou popularesca e folclórica. Aliás, tornei-me seu amigo por essa razão e muito temos conversado sobre a possibilidade de divulgação do nosso folclore, mesmo através de arranjos ${ }^{8}$.

Ainda sobre as tentativas de formação de um público consumidor, vale destacar duas iniciativas por parte da indústria, no início da década de 1970, narradas por José de Souza Martins no seu livro Capitalismo e Tradicionalismo.

Uma delas é o programa de televisão "Viola com Sortedada" (Canal 7, São Paulo, domingos, 9h), que tem uma parte dedicada a calouros com o júri formado 
por um alfaiate, um representante de sociedade de direitos autorais e por dois compositores. Os compositores avaliavam a instrumentação e a interpretação, o alfaiate o vestuário e o outro jurado a letra da música.

A outra tentativa foi a gravação do LP Nhô Look ("Nhô Look"- As mais Belas Canções Sertanejas, Orquestra e Coro, selo Fontana, FTLP 69.043, 1970), com direção e orquestração a cargo de Rogério Duprat. O produto pretendia apresentar a "nova" música sertaneja visando atingir um grande público em potencial.

A técnica da junção (tentativa de levar a música sertaneja para a circunstância de uma classe "média" mais definida, tanto em termos de recursos quanto em termos de valores e concepções do mundo) é a da "limpeza" da música sertaneja, principalmente pela reeducação do compositor: eliminação da linguagem "deformada" e estigmatizada, eliminação da pieguice e sua substituição por uma saudade mais convenientemente pequeno-burguesa a moderada saudade da cidade de origem ou o "sertão mítico" (...) (Martins, 1975, p. 126).

\section{Considerações finais}

Este trabalho busca trazer elementos para uma compreensão de como se deu, inicialmente, o registro da nossa música tradicional em discos. De certa forma, procura entender o percurso que as gravadoras fizeram no sentido de despertar o interesse do público consumidor para esse tipo de música.

O que observamos, a partir de informações das contracapas e partes internas dos Long-plays e de outros documentos citados no decorrer do texto, é que as gravadoras não acreditavam que manifestações musicais tradicionais pudessem, em seu estado puro, atrair o público consumidor. Por conta disso, usaram de vários recursos para tornar atrativos os seus discos, como orquestrações e cantoras consagradas pela mídia.

Acreditamos que jogar luz nos primórdios deste processo nos ajuda a entender o que veio a seguir, a gravadora Marcus Pereira, na produção de seus discos de música tradicional, e os desdobramentos que se fizeram nos novos formatos de mídia.

\section{Referências bibliográficas}

CORRÊA, Roberto Nunes. A Arte de Pontear Viola. Brasília: Viola Corrêa, 2002.

FERRETE, J. L. Capitão Furtado: viola caipira ou sertaneja? Rio de Janeiro: MINC/ FUNARTE, 1985.

MARTINS, José de Souza. Capitalismo e Tradicionalismo: estudos sobre as contradições da sociedade agrária no Brasil. São Paulo: Livraria Pioneira Editora, 1975.

TONI, Flávia Camargo. Missão: as pesquisas folclóricas. Ensaio do livreto da coleção de Cds: Mário de Andrade - missão de pesquisas folclóricas-1938. São Paulo: SESC SP/ Prefeitura da cidade de São Paulo /Secretaria Municipal de Cultura / Centro Cultural de São Paulo, 2006.

Eu Victrolo, tu victrolas, ele victrola. In: A Música Popular Brasileira na Vitrola de Mário de Andrade. TONI, Flávia Camargo (org.). São Paulo: SENAC São Paulo / SESC São Paulo, 2004.

VICENTE, Eduardo. Chantecler: uma gravadora popular paulista. In: Revista da USP. São Paulo: USP, n.87, setembro/novembro 2010, p. 56-73. 